\title{
Masked orthographic priming in bilingual word recognition
}

\author{
RANKA BIJELJAC-BABIC and AGNÈS BLARDEAU \\ CNRS and the University of Poitiers, Poitiers, France \\ and \\ JONATHAN GRAINGER \\ CNRS and the University of Provence, Aix-en-Provence, France
}

\begin{abstract}
Two lexical decision experiments tested the influence of briefly presented orthographically related primes on target word recognition in bilinguals. The prime stimuli were high-frequency words either from the same language as that of the target or from the other language known by the bilingual subjects. When the prime and target were from the same language, orthographically related primes systematically inhibited target word recognition, whereas orthographically dissimilar primes did not. When the prime and target were words from different languages, the amount of inhibition increased as a function of subjects' level of proficiency in the prime word's language, with highly proficient bilinguals showing practically equivalent amounts of within and across language inhibitory priming. These results strongly suggest that a printed string of letters can simultaneously activate lexical representations in both of the bilingual's languages (insofar as these share the same alphabet), even when subjects are performing a monolingual task.
\end{abstract}

In this article, we examine the early phases of visual word recognition in bilinguals-in particular, the representations and processes that are involved in recognizing that a given string of letters is a word in one specific language. When both of the bilingual's languages share the same alphabet and hence a certain degree of orthographic structure, there will be some ambiguity in early phases of processing with respect to the language to which the stimulus string belongs. Such ambiguity, however, is rarely felt by the bilingual reader, since the reading situation imposes such a high degree of constraint with respect to the language of the words that are read (code mixing is a very rare phenomenon in written language). The question, therefore, is whether such contextual knowledge can influence bilingual word recognition, and if so, how?

\section{Language-Specific Versus \\ Language-Independent Access}

One of the long-standing debates in the psycholinguistic literature concerns whether bilingual subjects can control access to only those representations that belong to the language that is specified by the communicational context (when reading a book in one language or listening to a monolingual speaker of one language). According to the

The authors would like to thank Joan Snodgrass and an anonymous reviewer for their helpful comments on an earlier version of this article. We would also like to thank Walter Van Heuven for running the simulation on the BIA model. Correspondence should be addressed to R. Bijeljac-Babic, Laboratoire Langage et Communication, Université de Poitiers, 99 Av. du Recteur Pineau, F-86022 Poitiers, France (e-mail: ranka.bijeljac@mshs.univ-poitiers.fr). selective-access hypothesis, stated in various forms by various authors (e.g., MacNamara \& Kushnir, 1971; Obler \& Albert, 1978; Scarborough, Gerard, \& Cortese, 1984), the answer to the question above is positive. Thus, for example, MacNamara and Kushnir (1971) proposed an input switch mechanism that guides sensory information to the appropriate lexical system (a set of language-specific representations involved in transcoding the sensory input). In this way, the bilingual person avoids interference from the other language when communicating in a strictly monolingual situation (as described above).

Research showing detrimental effects of code switching on language comprehension (Kolers, 1966; MacNamara, 1967; MacNamara \& Kushnir, 1971) has been taken as evidence for the selective-access hypothesis. Thus, bilingual subjects take longer to read sentences composed of words from both of their languages than they take to read normal, single-language sentences. Soares and Grosjean (1984) have demonstrated that this cost of processing incurred by mixing languages arises immediately during the recognition of the word directly following a code switch. These authors interpret the mixed-language effect in terms of the selective-access hypothesis. Sensory input is guided to the lexical system according to contextual information. Thus, when code switching occurs, the inappropriate lexical system is used to process the stimulus word; this is followed by transfer to the other lexical system and delayed recognition (Soares \& Grosjean, 1984). Grainger and Beauvillain (1987) have shown that the detrimental effects of changing from one language to another also arise in lists of unrelated words and therefore cannot be solely attributed to problems of integration of word meanings in sentence comprehension. 
Other data supporting the selective-access hypothesis have been reported by Scarborough et al. (1984). These authors observed that in a monolingual lexical decision task (i.e., a task in which the subject responds positively only if the stimulus is a word in a prespecified language, referred to as the target language), bilingual subjects responded negatively to words of the non-target language with the same speed as that with which they responded negatively to regular nonwords. According to these authors, the bilingual subjects were selectively accessing the target language lexicon and treating the other language words as nonwords. Nas (1983), however, has reported data from a similar experimental situation which demonstrate that non-targetlanguage words are rejected more slowly and less accurately than nonword stimuli. As already suggested by Grainger (1993), these conflicting results might be due to the different bilingual populations that were tested in the two studies (Spanish-English and Dutch-English, respectively). It might be the case (and this hypothesis remains to be tested) that the Spanish-English bilinguals of the Scarborough et al. study were able to use language-specific orthographic cues (e.g., the terminal A in Spanish, which is quite infrequent in English) to quickly reject some of the Spanish words as not being English words. On the other hand, the Dutch words used by Nas generally did not contain orthographic patterns that are infrequent in English (e.g., the Dutch words BLAD and MANK both contain letter combinations that occur frequently in English), and therefore the subjects in Nas's experiment could not have used such cues to quickly reject the non-target-language words. In favor of this interpretation, Grainger and Beauvillain (1987) showed that in a bilingual lexical decision task (in which subjects respond positively if the stimulus is a word in either language), the presence of language-specific letter clusters allowed subjects to avoid the extra cost in processing that was incurred when the directly preceding stimulus was a word from the other language.

The use of cross-language homographs (words that are spelled the same in two languages but have distinct meanings and pronunciations) to test the selective access hypothesis has also yielded conflicting results. In a study inspired by the monolingual work of Swinney (1979) and Simpson and Burgess (1985), Beauvillain and Grainger (1987) demonstrated that both meanings of such crosslanguage homographs are available independently of the language context of the experiment (French monolingual lexical decision or English monolingual lexical decision). Thus, for example, when subjects were instructed to read the prime stimulus as an English word, homographic primes facilitated the recognition of French target words that were related to the French meaning of the prime (e.g., chat-CHIEN) at short stimulus onset asynchronies (SOAs). In agreement with the results of Simpson and Burgess, these experiments demonstrated that the relative frequency of the different meanings rather than the context determined priming effects at short SOAs. With longer SOAs, context-inappropriate meanings no longer produced facilitation, thus suggesting a preliminary phase of nonselective access followed by context-dependent selection.

However, in apparent contradiction with this conclusion, Gerard and Scarborough (1989) reported that SpanishEnglish bilinguals responded to cross-language homographs as a function of their frequency of occurrence in the target language in a monolingual lexical decision task (in which subjects respond positively only if the letter string is a word in a prespecified language). Thus, when the target language was Spanish, the word RED, which has a low printed frequency in Spanish and a relatively high frequency in English, was responded to with the same speed as were low frequency nonhomographic Spanish words. According to Gerard and Scarborough, these results can be taken as further support for the selectiveaccess hypothesis. However, it is clear that to respond correctly in a monolingual lexical decision task, the subject has to know not only that the stimulus is a word, but also that it is a word in the specified language. This, therefore, does not exclude the possibility that the non-targetlanguage meaning was also accessed (as is suggested by the results of Beauvillain \& Grainger, 1987) but was useless for the task at hand. Moreover, when homographic cognates (translation equivalents that are spelled the same) are used as stimuli, exactly the opposite effect is observed (Caramazza \& Brones, 1979). In this study, bilinguals performed a lexical decision task in their second language, and it was observed that cognate words were responded to more rapidly than noncognate stimuli, suggesting that they were being processed as words from the bilinguals' dominant language.

The selective-access hypothesis has often been attacked on the basis of data obtained from experimental paradigms designed to measure cross-language interference in bilingual subjects. Stroop color-word interference obtains independently of whether or not the interfering color word is in the same language as that used to read the ink color name aloud (Dyer, 1971). This cross-language Stroop interference has also been obtained in the flanker task (Guttentag, Haith, Goodman, \& Haugh, 1984) and in the picture-word interference task (Ehri \& Bouchard-Ryan, 1980). However, to be fair to the selective-access hypothesis, it should be noted that in these cross-language interference paradigms it is possible that sensory information from the written word was first processed by the inappropriate context-dependent lexical system before being transferred to the appropriate lexical system for successful identification. In other words, selective access implies only a priority in first accessing the lexical system specified by context; it does not mean that words from the nontarget language will never be recognized. They are recognized, but with extra processing compared with the words from the target language. Successful identification of the interfering word in this way could then lead to competition at later levels of processing (e.g., retrieval of phonological output codes for the naming response).

Thus, it should be clear from the preceding discussion that further evidence is required in order to settle the se- 
lective- versus non-selective-access issue. One particularly promising area to look for this evidence is in crosslanguage orthographic neighborhood effects.

\section{Neighborhood Effects Across Languages}

In experiments with monolingual subjects, it has been observed that the time to recognize a written word is influenced by the characteristics of words that are orthographically similar to the stimulus (Andrews, 1989; Grainger, 1990; Grainger, O'Regan, Jacobs, \& Segui, 1989; Grainger \& Segui, 1990; Snodgrass \& Mintzer, 1993). The point of interest here is whether such orthographic neighborhood effects extend across languages in bilingual subjects. According to the selective-access hypothesis, there should be no influence of nontarget language words on the recognition of target language stimuli. In addressing this issue, Van Heuven, Dijkstra, and Grainger (1997) have demonstrated strong inhibitory effects of orthographic neighbors from the nontarget language in a new experimental paradigm referred to as progressive demasking (Grainger \& Segui, 1990). In this paradigm, a target word becomes visible over time via reduced masking of the stimulus. Subjects simply have to press a response button when they have recognized a word, and then type in the word on the computer keyboard. Dutch-English bilinguals took longer to recognize English words that had many orthographic neighbors in Dutch than to recognize words that had few Dutch word neighbors, even when they were told that only English words would be presented. Although Van Heuven et al. also demonstrated that this cross-language neighborhood interference is to a certain extent controllable by bilingual subjects, the very fact that it is observable is strong evidence against a strict selective-access hypothesis.

The present experiments were designed to examine a further aspect of cross-language neighborhood effects in an attempt to provide additional data on this critical point. In monolingual experimentation, it has been demonstrated that the inhibitory effects of orthographic neighbors on visual word recognition can be enhanced by briefly presenting the neighboring word as a prime stimulus immediately before target word presentation. In conditions in which such prime stimuli were barely visible (very brief exposures and forward masking), Segui and Grainger (1990) observed inhibitory effects of high-frequency neighbors on low-frequency target words (an English example would be BLUE-BLUR), in comparison with a control condition in which the prime word was unrelated to the target (orthographically, phonologically, and semantically). However, no such effect was obtained when the prime stimuli were low frequency and the targets high frequency. This strongly suggests that these inhibitory effects of form priming are the result of lexically based competition processes. Moreover, the fact that in similar conditions nonword prime stimuli tend, if anything, to facilitate the recognition of orthographically related target words (Ferrand \& Grainger, 1992; Forster, Davis, Scho- knecht, \& Carter, 1987) further confirms the lexical locus of the inhibitory priming effect.

This inhibitory effect has since been replicated in several studies (e.g., Drews \& Zwitserlood, 1995; Grainger, Colé, \& Segui, 1991; Grainger \& Ferrand, 1994). Within the framework of the interactive activation model (McClelland \& Rumelhart, 1981), the effect can be explained by simultaneously activated word units inhibiting the rise in activation of the target word representation. The prime stimulus serves to preactivate a lexical representation that will continue to receive excitatory input during target word processing (because of orthographic overlap with the target). Since the activation level of lexical representations is also a function of their printed frequency, this model correctly predicts that maximum interference will occur when the prime is a high-frequency word and the target, low frequency. Jacobs and Grainger (1992) have shown that a semistochastic variant of the interactive activation model can indeed provide accurate simulations of the results reported by Segui and Grainger (1990).

The present experiments were designed to examine whether, in bilingual subjects, orthographically related words from different languages would produce the inhibitory effects typically observed with words from the same language. Moreover, by testing for effects of orthographic priming in beginning and proficient bilinguals, we examined how degree of fluency in the second language affected between-language orthographic priming. According to the selective-access hypothesis, no effects of other language primes should be observed. On the other hand, if one were to observe such cross-language neighborhood priming effects, this would be strong evidence in favor of a model of bilingual word recognition in which sensory information simultaneously contacts lexical representations from both languages. Moreover, such a result would also indicate that these lexical representations form an integrated network. More specifically, within the explanation of inhibitory orthographic priming provided by the interactive activation model, this would imply that inhibitory connections among word units extend across languages. In Experiment 1, we tested this hypothesis with a group of highly proficient bilinguals. Since the monolingual studies have shown that inhibitory priming effects are strongest with high-frequency prime words (Segui \& Grainger, 1990), we expected that higher levels of second language proficiency would increase the likelihood of observing cross-language priming.

\section{EXPERIMENT 1}

\section{Method}

Stimuli and Design. All prime and target stimuli were four letters long. The primes were French or English words with high print frequencies. For French primes, the mean print frequency was 388 occurrences per million (Imbs, 1971), and for English primes, 266 occurrences per million (Kučera \& Francis, 1967). The targets were either low-frequency English words (with a mean frequency of 24 occurrences per million, Kučera \& Francis, 1967), or nonwords that 
were orthographically legal and pronounceable in English. Each subject received all the 96 targets ( 48 words and 48 nonwords). Half of the targets were preceded by French prime words, and the other half, by English words, giving the two levels of the within-subjects factor prime language. Within each of the prime language conditions, half of the targets were preceded by orthographically related primes (sharing three out of four of the target's letters respecting position; e.g., help-HELM; joie-JOIN), and the other half were preceded by primes that had no letters in common in the same position in the word (e.g., rich-HELM; acte-JOIN), defining the two levels of the within-subjects factor relatedness. Thus prime language (French or English) and relatedness were crossed in a $2 \times 2$ factorial design. Prime-target relatedness was rotated across two groups of subjects so that each target word was preceded by a related and an unrelated prime in different subjects (the prime target pairs are presented in Appendix A). Nonword targets were constructed by changing one letter of a four-letter English word (not used as a word target) to produce pronounceable, orthographically legal, nonsense strings of letters. Twenty-four nonword targets were preceded by orthographically related word primes: 12 in English (e.g. felt-FILT) and 12 in French (e.g. bleu-BLEE). A further 24 nonword targets were preceded by orthographically unrelated word primes, 12 in English (rest-DELM) and 12 in French (paix-REWs). The experiment started with 16 practice trials, in which a randomly ordered set of 8 English words and nonwords was preceded by either related or unrelated French and English prime words, all different from the experimental trials. All practice stimuli were four letters long and of the same average frequency as the experimental stimuli.

Procedure. The stimuli were presented in isolation at the center of an IBM-compatible computer screen with a $70-\mathrm{Hz}$ refresh rate. The stimuli appeared as white letters on a dark background. The primes were printed in lowercase letters, and the targets, in uppercase letters, in order to minimize physical overlap in the orthographically related pairs. The masked prime procedure combined with the lexical decision task as first used in the experiments of Segui and Grainger (1990) was adopted here. Each trial started with the presentation of a forward mask, consisting of a row of four hash marks (\#), for $500 \mathrm{msec}$, followed immediately by the prime for $57 \mathrm{msec}$. The prime was immediately followed by the presentation of the target stimulus; both were presented at the same screen location as was the mask. The target remained on the screen until the subject responded. Stimulus presentation was randomized, with a different order for each subject. The subjects were tested individually. They were instructed to make a lexical decision to the stimuli in uppercase letters as rapidly and as accurately as possible. They were instructed to expect only English words or nonwords. The existence of a prime stimulus was not mentioned. The subjects responded "yes" by pressing one of two response buttons with the forefinger of their dominant hand and "no" by pressing the other response button with the forefinger of the nonpreferred hand. The next sequence followed after a 1-sec delay. Reaction time was measured from the onset of the target.

Subjects. Ten highly proficient French-English bilinguals participated in Experiment 1 . These subjects had been exposed to both languages from early childhood and continued to use them daily at work and/or at home.

\section{Results}

All reaction times (RTs) exceeding $1,500 \mathrm{msec}$ and below $300 \mathrm{msec}$ ( $1.6 \%$ of the data) were excluded from the analysis. Mean correct lexical decision latencies and mean percentage of errors to word targets are given in Table 1. An analysis of variance was performed on the RTs to word targets, with subjects $\left(F_{1}\right)$ and items $\left(F_{2}\right)$ as random variables.
Table 1

Mean Correct Response Times and Percentage of Errors (With Standard Errors) of Lexical Decisions Made by Proficient Bilingual Subjects to the English Target Word

Stimuli Which Were Preceded by Orthographically Related or Unrelated English (Same-Language) or French (Different-Language) Word Primes in Experiment 1

\begin{tabular}{|c|c|c|c|c|c|c|c|c|}
\hline \multirow[b]{3}{*}{ Measure } & \multicolumn{4}{|c|}{ Same Language } & \multicolumn{4}{|c|}{ Different Languages } \\
\hline & \multicolumn{2}{|c|}{ Related } & \multicolumn{2}{|c|}{ Unrelated } & \multicolumn{2}{|c|}{ Related } & \multicolumn{2}{|c|}{ Unrelated } \\
\hline & $M$ & $S E$ & $M$ & $S E$ & $M$ & $S E$ & $M$ & $S E$ \\
\hline RT & 732 & 37.3 & 704 & 28.7 & 688 & 22.4 & 634 & 18.9 \\
\hline$\%$ Err & 25.8 & 5.3 & 15 & 2.9 & 9.1 & 1.7 & 9.1 & 2.6 \\
\hline
\end{tabular}

Word targets preceded by orthographically related primes were responded to $41 \mathrm{msec}$ more slowly than were word targets preceded by unrelated primes $\left[F_{1}(1,9)=\right.$ $\left.5.22 ; p<.05 ; F_{2}(1,46)=10.84, p<.01\right]$. Same-language primes produced slower RTs than did different-language primes $\left[F_{1}(1,9)=6.42, p<.05 ; F_{2}(1,46)=28.98, p<\right.$ $.001]$. The relatedness $\times$ prime language interaction was not significant (both $F \mathrm{~s}<1$ ). An analysis of the error percentages by subject showed no significant effect of relatedness $[F(1,9)=1.67]$. Same-language primes produced more errors than did different language primes $[F(1,9)=$ $8.73 ; p<.05]$. Prime language did not interact with relatedness $[F(1,9)=2.73]$. An analysis of responses to the nonword targets revealed no main interaction effects in the RT data. Significantly more false positive errors were made to nonword targets preceded by orthographically related primes $(10.8 \%)$ than to nonword targets preceded by orthographically unrelated primes $(6.7 \%)[F(1,9)=$ $6.43, p<.05$ ]

\section{Discussion}

The results of Experiment 1 lend support to the nonselective access hypothesis, according to which a given string of letters will activate lexical representations in both of the bilingual's languages, independently of language context. Such a hypothesis has been recently implemented in the bilingual interactive activation (BIA) model (Grainger, 1993; Van Heuven et al., 1997). In this model, the orthographic representations of words are linked together via inhibitory connections in an integrated network. Within this network, the more a given unit is activated, the more it inhibits all the other units (as in the original interactive activation-model; McClelland \& Rumelhart, 1981). The inhibitory effects of masked orthographic priming are therefore the result of the prime word representation's reaching a relatively high activation level during processing of the target and thus inhibiting the rise in activation of the target word (Jacobs \& Grainger, 1992).

One other important characteristic of the BIA model implemented by Van Heuven et al. (1997) is the presence of language nodes that collect activity from all word units in the appropriate language. As activation develops in a given language node, this leads to a generalized inhibition of all word units in the other language(s). This top- 
down language-to-word inhibition can be thought of as a language filter that acts to reduce interference from the nontarget language (Van Heuven et al., 1997). However, the fact that different-language primes actually produced faster RTs than did same-language primes and fewer errors than did same-language primes in Experiment 1 contradicts the predictions of the BIA model. According to this model, when the prime is a word from the nontarget language, there will be a rise in nontarget language node activity followed by the general inhibition of all word units in the target language. One would therefore expect to observe slower RTs in the different-language prime condition, if anything. It should, however, be noted that different target words were tested in the two levels of the prime language factor, and so the observed effects of this factor might have been due to uncontrolled differences (such as within and between-language neighborhood characteristics) between these two sets of target words. One simple means of testing this possibility is to run a simulation on the BIA model with an integrated English-French lexicon of four-letter words. ${ }^{1}$ Using the simulation technique for masked priming studies described in Jacobs and Grainger (1992), we ran deterministic simulations for all the prime-target pairs tested in
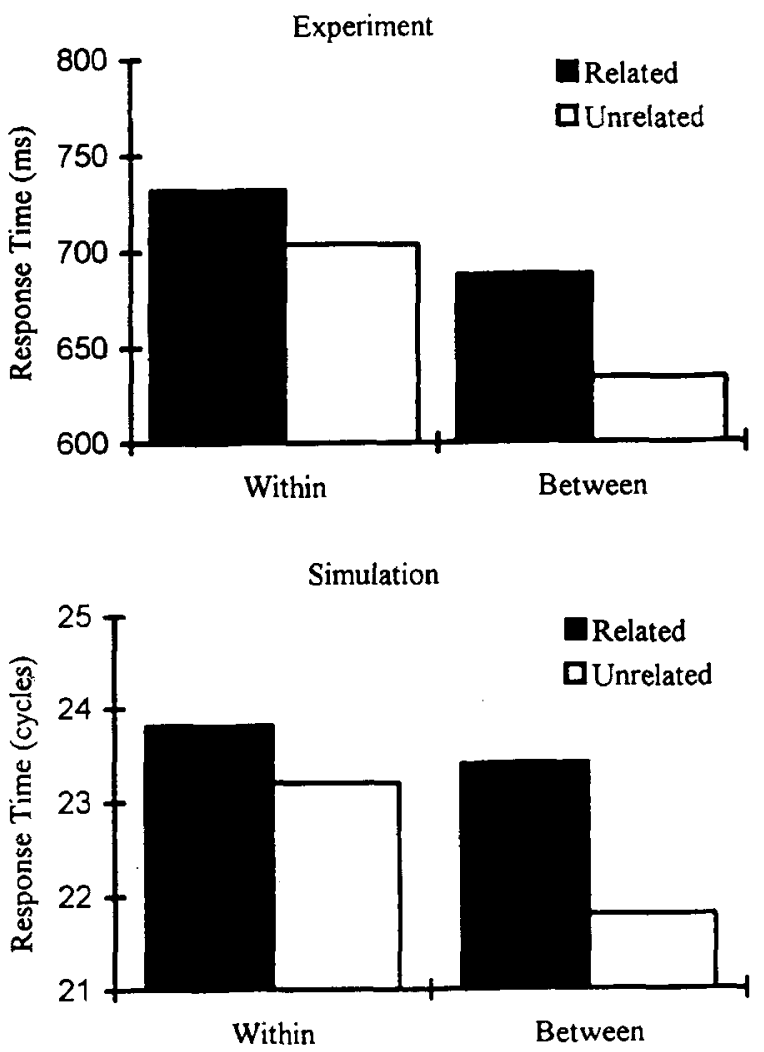

Figure 1. Mean response time to English word targets preceded by or thographically related or unrelated English (within) and French (between) word prime stimuli in Experiment 1 and in the corresponding simulation run on the BIA model (Van Heuven et al., 1997).
Experiment 1 . The results of this simulation are presented alongside the experimental results in Figure 1.

The simulation captures not only the longer average RTs in the within-language prime condition but also the trend toward larger priming effects in the between-language primes. Since the model only encodes word frequency (in terms of resting level activation) and orthographic similarities between words, this indicates that the neighborhood characteristics of the English targets used in the within-language priming condition rendered these stimuli easier to recognize than the targets tested in the between-language priming condition. This may be because the within-language targets all had high-frequency within-language neighbors (the prime word), whereas the between-language targets did not systematically have such high-frequency within-language neighbors. Van Heuven et al. (1997) have shown that the inhibitory effects of within-language neighbors are indeed stronger than those provoked by between-language neighbors when bilinguals perform a word identification task in their dominant language.

In the BIA model, the strength of lexical competition is a function of the activation levels of competing units. The higher the activation levels of these units, the stronger the inhibition. In the monolingual situation, two factors determine the activation levels of competing units: orthographic overlap with the target, and print frequency of the word unit (see Grainger, 1992, for a detailed discussion of this point). In the bilingual situation, however, amount of experience with the second language is likely to be an important factor in determining the degree of between-language lexical competition. Within the interactive activation framework, it is hypothesized that the amount of exposure to a given word determines the word's resting level activation. Clearly, degree of proficiency in a second language is highly correlated with amount of exposure to that language and should therefore determine the resting level activations of lexical representations in that language. Proficiency in the language of the prime stimuli should therefore have an effect analogous to word frequency. Higher levels of proficiency should provoke stronger inhibition.

In Experiment 2, we tested the hypothesis that betweenlanguage orthographic inhibition increases with higher levels of second-language proficiency (the language in which the different-language prime stimuli are presented). Moreover, because of the importance of the results of Experiment 1 with respect to the selective versus nonselective access issue, Experiment 2 provided a replication with a different set of prime-target stimuli (changing target language) in order to demonstrate that the effect would generalize over different samples of stimuli.

\section{EXPERIMENT 2}

In Experiment 2, we tested the same set of targets in the between- and the within-language priming conditions in 
three groups of French-speaking subjects who differed with respect to their fluency in English: proficient bilinguals, beginning bilinguals, and monolinguals (although these subjects obviously did have some knowledge of English).

\section{Method}

Stimuli and Design. All prime and target stimuli were four to five letters long. All target words were French words with relatively low print frequencies (mean frequency: 42 occurrences per million; Imbs, 1971). The prime stimuli were French and English words with high print frequencies. The mean frequency of French primes was 388 occurrences per million (Imbs, 1971); for the English primes, it was 266 occurrences per million (Kučera and Francis, 1967). Each subject received 64 targets ( 32 words and 32 nonwords). In this experiment, we used the same target words in the within- and between-language prime-target conditions, thus imposing even tighter constraints on stimulus selection than in Experiment $1 .{ }^{2}$ Four experimental lists were necessary in order to rotate primetarget pairings across the four conditions in which a given target was tested. For example, the words that were preceded by English related primes in List 1 (e.g., soil-SOIF) were preceded by French related primes in List 2 (e.g., soin-SOIF), by English unrelated primes in List 3 (e.g., gray-SOIF), and finally by French unrelated primes in List 4 (e.g., huit-SOIF). Thirty-two nonword targets were constructed for the purposes of the lexical decision task. The nonwords were constructed by changing a letter in four-or five-letter French words to produce a pronounceable orthographically legal nonsense string of letters. Each nonword target was preceded by an orthographically similar word prime in English (e.g., army-ARNE), by a related word in French (e.g., arme-ARNE), by an unrelated English prime (e.g. book-ARNE), and finally by an unrelated French word (e.g., bois-ARNE). The 32 nonword targets were organized in four lists, as for the word targets. As in the previous experiment, subjects received a series of 16 practice trials of the same type as the experimental trials. Any given subject in a given bilingual group was presented with one list only. Thus, no subject saw any prime or target word more than once but each subject received all four experimental conditions and each target appeared with each of its four possible primes across the different groups of subjects.

Procedure. The same procedure as in the previous experiment was used here, except that subjects were instructed to expect only French words or nonwords as targets. As before, no mention was made of the presence of prime stimuli.

Subjects. Three groups of French-speaking students were tested: a group of 20 proficient French-English bilinguals, a group of 20 beginning French-English bilinguals, and a group of 20 French monolinguals. The beginning bilinguals were French students of
English at the University of Poitiers, and the monolingual subjects were students of psychology at the same university. The proficient bilinguals were taken from the same population as in Experiment 1 but had not participated in this experiment.

\section{Results}

All reaction times exceeding $1,500 \mathrm{msec}$ and below $300 \mathrm{msec}$ ( $1.4 \%$ of the data) were excluded from the analysis. The mean lexical decision latencies and percentage of errors to words targets are given in Table 2. An analysis of variance was performed on the RT data to word stimuli with subjects $\left(F_{1}\right)$ and items $\left(F_{2}\right)$ as random variables.

Targets preceded by orthographically related primes were responded to $32 \mathrm{msec}$ more slowly than were targets preceded by unrelated primes $\left[F_{1}(1,57)=18.09, p<\right.$ $\left..001 ; F_{2}(1,31)=5.95, p<.05\right]$. Different-language primes tended to slow target processing compared to samelanguage primes $\left[F_{1}\left(1,57=5.96, p<.05 ; F_{2}(1,31)=\right.\right.$ 1.47]. The main effect of proficiency was not significant in the analysis by subjects $\left[F_{1}(2,57)=1.4 ; F_{2}(2,62)=\right.$ $5.95, p<.05]$. The triple interaction was not significant $\left[F_{1}(2,57)=1.19 ; F_{2}<1\right]$, and none of the two-way interactions reached statistical significance (all $F \mathrm{~s}<1$ ). However, with respect to the specific hypothesis under test in the present study, it is important to note that the effects of relatedness in the different-language prime condition gradually increased as a function of the subjects' level of proficiency, becoming robust only in the proficient bilingual group $\left[F_{1}(1,19)=8.86, p<.01 ; F_{2}(1,31)=4.13\right.$, $p<.05]$. Furthermore, the inhibitory effects of different language primes, independently of effects of orthographic relatedness, only started to approach statistical significance in the proficient bilingual group $\left[F_{1}(1,19)=5.06\right.$, $\left.p<.05 ; F_{2}(1,31)=1.69\right]$.

An analysis of variance of the percentage of errors by subjects showed that significantly more errors were made to targets preceded by related primes $[F(1,57)=5.38$, $p<.05]$. The other main effects did not reach statistical significance, but there was a significant triple interaction $[F(2,57)=7.76, p<.01]$. The effects of relatedness significantly interacted with prime language in the monolingual group $[F(1,19)=11.81, p<.01]$, with facilitatory

Table 2

Mean Correct Response Times and Percentage of Errors (With Standard Errors) of Lexical Decisions Made by Monolinguals, Beginning Bilinguals, and Proficient Bilingual Subjects to the French Target Word Stimuli Which Were Preceded by Orthographically Related or Unrelated French (Same-Language) or English (Different-Language) Word Primes in Experiment 2

\begin{tabular}{|c|c|c|c|c|c|c|c|c|c|}
\hline \multirow[b]{3}{*}{ Subjects } & \multirow[b]{3}{*}{ Measure } & \multicolumn{4}{|c|}{ Same Language } & \multicolumn{4}{|c|}{ Different Languages } \\
\hline & & \multicolumn{2}{|c|}{ Related } & \multicolumn{2}{|c|}{ Unrelated } & \multicolumn{2}{|c|}{ Related } & \multicolumn{2}{|c|}{ Unrelated } \\
\hline & & $M$ & $S E$ & $M$ & $S E$ & $M$ & $\overline{S E}$ & $M$ & $S E$ \\
\hline \multirow[t]{2}{*}{ Monolinguals } & RT & 740 & 21.0 & 690 & 17.6 & 734 & 19.3 & 730 & 19.8 \\
\hline & $\% \operatorname{Err}$ & 19.6 & 2.9 & 10.1 & 2.8 & 12.7 & 2.4 & 18.4 & 2.9 \\
\hline \multirow[t]{2}{*}{ Beginning bilinguals } & $\mathrm{RT}$ & 785 & 21.9 & 734 & 26.1 & 769 & 18.5 & 752 & 21.3 \\
\hline & $\% \mathrm{Err}$ & 6.4 & 1.7 & 7.6 & 2.1 & 15.1 & 2.9 & 9 & 1.9 \\
\hline \multirow[t]{2}{*}{ Proficient bilinguals } & RT & 757 & 25.5 & 729 & 18.6 & 792 & 20.0 & 749 & 17.4 \\
\hline & $\%$ Err & 14.0 & 3.0 & 7.0 & 2.5 & 13.3 & 3.2 & 8.9 & 2.7 \\
\hline
\end{tabular}


effects appearing in the different-language prime condition to inhibitory effects in the same-language prime condition. On the contrary, no such interaction was observed in the proficient bilinguals, with inhibitory effects of relatedness appearing in both the same- and the differentlanguage prime conditions. An analysis of variance by subjects of the RTs and percentage errors to nonword targets revealed only one significant effect in these data. French word primes provoked slower correct negative RTs than did English word primes $[F(1,57)=6.6, p<.05]$.

\section{Prime Visibility}

Although the primes were masked and presented very briefly, and their presence was not mentioned to the subjects, it is possible that some subjects may have identified some of the prime words. However, when questioned after the experiment, none of the subjects in Experiment 2 ever reported having identified a word in lowercase letters presented briefly before the target in uppercase letters. Furthermore, an additional group of 10 monolingual French speakers was tested in exactly the same experimental conditions while being informed of the presence of French words as prime stimuli. No subject ever reported having identified a prime word. This suggests that prime word visibility remained minimal in the present testing conditions.

\section{Discussion}

The results of Experiment 2 confirm the existence of cross-language inhibitory orthographic priming in proficient bilinguals and demonstrate that these priming effects diminish as proficiency in the second language diminishes. The performance of French monolingual subjects showed no influence of English word primes, thus demonstrating that the effects observed in the beginning and proficient bilinguals cannot have been prelexical in origin. On this point, it is important to note that orthographically related nonword primes typically produce either facilitatory effects (Forster et al., 1987) or null effects (Ferrand \& Grainger, 1992, 1994) in the experimental conditions used here. In other words, the inhibitory effects of different-language primes in subjects are likely to be due to the prime word's lexical representation in some way interfering with target word recognition. The fact that nonword targets were not significantly affected by orthographically related word primes in the present experiments adds further support to this conclusion. The possible mechanisms underlying these interference effects will be examined in what follows.

\section{GENERAL DISCUSSION}

The present experiments not only provide a clear replication of previous studies showing within-language inhibitory form priming effects in the masked prime paradigm (Drews \& Zwitserlood, 1995; Grainger et al., 1991; Grainger \& Ferrand, 1994; Segui \& Grainger, 1990), but more importantly demonstrate that similar effects also occur across languages in bilingual subjects. When presented with a low-frequency word to recognize in one language, the proficient bilinguals tested in the present research were significantly slower to respond when this target word was preceded by a high-frequency orthographically related word from the nontarget language than when the prime word was an orthographically unrelated word of similar frequency also from the nontarget language. These cross-language inhibitory form priming effects were not statistically significant in the beginning bilingual subjects of Experiment 2, and they were totally absent in the monolingual subjects of this experiment (see Table 2). Since in the cross-language situation the target was always in the native language and the prime in the second language of these low-proficiency subjects, the latter result adds support to the hypothesis that inhibitory form priming in the masked priming paradigm is a function of the subjective frequency (the number of times a given person has been exposed to a given word) of prime words. Beginning bilinguals have had significantly less exposure to words of their second language, so the majority of the second language prime words can be considered to have low subjective frequency in comparison with comparable high-frequency words of the native language. The fact that no cross-language priming effects were observed in the monolingual subjects provides a replication of the observed absence of orthographic priming with nonword primes at such prime exposure durations (Ferrand \& Grainger, 1992; Grainger \& Ferrand, 1994).

These results stand in clear contradiction to the selectiveaccess hypothesis presented in the introduction. According to this hypothesis, when one performs a monolingual lexical decision task as in the present experiments, on each trial sensory information extracted from the target will contact only the lexical representations that belong to the target language; in the present instance, no effects of nontarget language primes should have been observed in the present experiments. These results therefore provide support for a model of visual word recognition in bilinguals that postulates parallel access to lexical representations from both languages, with these representations being stored in an integrated network. So as to avoid any confusion at this point, it should be noted that we are referring to an integrated network at the level of whole-word orthographic representations and are not making any claims as to whether such integration is maintained at other representational levels.

The important aspect of the present results and those of Van Heuven et al. (1997) is that cross-language interference was detected even when subjects were responding to words of only one language (monolingual lexical decision in the present experiments and monolingual progressive demasking in the experiments of Van Heuven et al.). Any attempt to improve performance in these conditions would have led subjects to reduce this cross-language interference. The fact that such effects are observed is therefore strong evidence for an irrepressible initial activation 
of lexical representations in both languages. Thus, the present results, along with those of Grainger and Dijkstra (1992) and Van Heuven et al. (1997), suggest that lexical representations that share orthographic information with the stimulus are simultaneously activated independently of the language they belong to. This concept of an initially language-independent multiple access in bilingual word recognition was implemented in the BIA model of Van Heuven et al. In this model, a given stimulus string activates all word units in both languages that share letters with the stimulus. These word units are all interconnected with inhibitory links, so that when one unit is activated, all other units are inhibited at that level. These inhibitory connections among word units allow the model to accurately predict the detrimental effects of increasing number of neighbors on word recognition performance in monolinguals (Snodgrass \& Mintzer, 1993) and bilinguals (Van Heuven et al., 1995). The same mechanism allows the model to capture the inhibitory effects of orthographically related prime stimuli (Jacobs \& Grainger, 1992; Segui \& Grainger, 1990). The fact that these inhibitory connections extend across languages in the BIA model therefore allowed it to predict correctly the presence of cross-language inhibitory priming observed in the proficient bilinguals of the present experiments (see Figure 1).

Alternatively, the nonselective access hypothesis could also be implemented within the framework of the activation verification model (Paap, Newsome, McDonald, \& Schvaneveldt, 1982). One of the authors (Grainger, 1993) has already presented a verbal extension of this model to the bilingual situation. In the bilingual activation verification (BAV) model, whole-word orthographic representations are stored in separate lexica. Orthographic information extracted from the stimulus initially activates a set of lexical candidates in both languages, independently of language context. It is only in later selection/verification processes that information concerning the language of the stimulus can come into play. At that point, the verification process can be directed by language context information to the most likely lexicon and search begins on the set of candidates in that particular language. The verification process within each language is ordered by decreasing frequency of occurrence, thus capturing word frequency effects, and search continues from one language to the other if a match is not detected in the candidates of the first lexicon to be searched.

Thus, in order to capture the detrimental effects of code mixing, the BAV model has to postulate separate stores for the orthographic representations of words from each language. Context guides the verification process to the set of candidates belonging to the appropriate language. The problem is that such a model predicts a total absence of cross-language neighborhood effects. As stated in the general conclusions above, the present results, along with the results of Grainger and Dijkstra (1992), Grainger and O'Regan (1992), and Van Heuven et al. (1997), all suggest the existence of an integrated set of orthographic representations from both languages. However, an integrated lexicon BAV model can no longer accommodate the data on language-switching effects. One way to circumvent this problem, as already suggested by Grainger (1993), is to maintain distinct lexica and further postulate that the relative activation levels in each lexicon will determine which set of candidates is checked first. In this way, a prime word from the nontarget language could raise the activation level of the nontarget lexicon. If this prime word is orthographically related to the following target, its lexical representation will continue to receive activation during target word recognition and therefore continue to raise the activation level of the nontarget lexicon. In this way, target word recognition will be delayed by the prior verification (and subsequent rejection) of the prime word. Clearly, the BAV model merits a computer implementation, since only extensive simulation work on this type of model will allow a full evaluation of its potential.

The different models of visual word recognition in bilingual subjects presented in the preceding discussion both implement an initially nonselective access to the orthographic representations of words in both languages. They differ, however, in terms of whether or not such representations are part of an integrated network (the BIA model) or form two distinct lexica (the BAV model). The term integrated network as it is used here implies several things. First and foremost, at a functional level of analysis, it implies connectivity among all whole-word orthographic units within and between languages (i.e., the inhibitory connections between all word units in the BIA model). In anatomical terms, it probably (but not necessarily) implies a common representational area for the processing of whole-word orthography for the bilingual's two languages; this would be good (but not definitive) evidence in favor of the separate orthographic lexica hypothesis.

For example, an examination of bilingual patients suffering from specific word recognition deficits (related to the orthographic input lexicon), would provide valuable information concerning the organization of representations at this level. Unfortunately, we could find no published study concerning such patients (assuming they do exist). In a recent study, Klein, Zatorre, Milner, Meyer, and Evans (1995) examined brain activity in healthy volunteer bilinguals by using positron emission tomography, in single-word repetition and translation generation tasks. These authors found "strikingly similar" patterns of brain activity in the left anterior inferior frontal gyrus when performance was in the dominant or the second language of their bilingual volunteers. This study, however, was limited to spoken word recognition, and unfortunately did not disentangle the processing of forms (e.g., phonological forms) from semantic processing (see, e.g., Petersen, Fox, Snyder, \& Raichle, 1990). The neural substrates shared by both languages in the task used by Klein et al. may therefore simply reflect a common semantic network in bilinguals.

Clearly, only further research, whether with behavioral or with brain imaging techniques, will allow us to provide a detailed description of the representations and pro- 
cesses involved in bilingual word recognition. The present results provide some preliminary data that support a view of orthographic processing whereby whole-word orthographic representations in both of the bilingual's languages are automatically and simultaneously activated upon presentation of a string of letters, independently of the language context in which the letter string appears. Thus, to return to the question raised at the very beginning of the present article, one might legitimately ask, When does language context information influence the word recognition process? The answer provided by the BIA model (Van Heuven et al., 1997) discussed above is that almost immediately following the initial nonselective activation phase, language context information allows the suppression of context-incompatible representations (i.e., all words in the inappropriate language) via top-down inhibitory connections from language nodes to word representations. The present results simply show that nontarget language representations remain activated long enough for detectable inhibition to affect the target word representation. Further research manipulating the exposure duration of prime stimuli will allow us to compare the time courses of same-language and different-language orthographic priming.

\section{REFERENCES}

ANDREWS, S. (1989). Frequency and neighborhood size effects on lexical access: Activation or search? Journal of Experimental Psychology: Learning, Memory, \& Cognition, 15, 802-814.

Beauvillain, C., \& Grainger, J. (1987). Accessing interlexical homographs: Some limitations of a language-selective access. Journal of Memory \& Language, 26, 658-672.

Caramazza, A., \& Brones, I. (1979). Lexical access in bilinguals. Bulletin of the Psychonomic Society, 13, 212-214.

DREWs, E., \& ZWITSERLOOD, P. (1995). Morphological and orthographic similarity in visual word recognition. Journal of Experimental Psychology: Human Perception \& Performance, 21, 1098-1116.

DYER, F. N. (1971). Color naming interference in monolinguals and bilinguals. Journal of Verbal Learning \& Verbal Behavior, 10, 297-302.

EHRI, L. C., \& Bouchard-RYaN, E. (1980). Performance of bilinguals in a picture-word interference task. Journal of Psycholinguistic Research, 9, 285-303.

Ferrand, L., \& Grainger, J. (1992). Phonology and orthography in visual word recognition: Evidence from masked nonword priming. Quarterly Journal of Experimental Psychology, 45A, 353-372.

Ferrand, L., \& Grainger, J. (1994). Effects of orthography are independent of phonology in masked form priming. Quarterly Journal of Experimental Psychology, 47A, 365-382.

Forster, K. I., Davis, C., Schoknecht, C., \& Carter, R. (1987). Masked priming with graphemically related forms: Repetition or partial activation? Quarterly Journal of Experimental Psychology, 39A, 211-251.

Gerard, L. D., \& Scarborough, D. L. (1989). Language-specific lexical access of homographs by bilinguals. Journal of Experimental Psychology: Learning, Memory, \& Cognition, 15, 305-313.

GRAINGER, J. (1990). Word frequency and neighborhood frequency effects in lexical decision and naming. Journal of Memory \& Language, 29, 228-244.

GRAINGER, J. (1992). Orthographic neighborhoods and visual word recognition. In R. Frost \& L. Katz (Eds.), Orthography, phonology morphology and meaning (pp. 131-166). Amsterdam: North-Holland.

GRAINGER, J. (1993). Visual word recognition in bilinguals. In
R. Schreuder \& B. Weltens (Eds.), The bilingual lexicon (pp. 11-25). Amsterdam/Philadelphia: John Benjamins.

Grainger, J., \& Beauvillain, C. (1987). Language blocking and lexical access in bilinguals. Quarterly Journal of Experimental Psychology, 39A, 295-319

Grainger, J., Colé, P., \& Segul, J. (1991). Masked morphological priming in visual word recognition. Journal of Memory \& Language, 30, 370-384.

Grainger, J., \& Dijkstra, T. (1992). On the representation and use of language information in bilinguals. In R. J. Harris (Ed.), Cognitive processing in bilinguals (pp. 207-220). Amsterdam: Elsevier, NorthHolland.

Grainger, J., \& Ferrand, L. (1994). Phonology and orthography in visual word recognition: Effects of masked homophone primes. Journal of Memory \& Language, 33, 218-233.

GrainGER, J., \& O'REGAN, J. K. (1992). A psychophysical investigation of language priming effects in two English-French bilinguals. European Journal of Cognitive Psychology, 4, 323-339.

Grainger, J., O'Regan, J. K., Jacobs, A. M., \& Segui, J. (1989). On the role of competing word units in visual word recognition: The neighborhood frequency effect. Perception \& Psychophysics, 45, 189-195. GRAINGER, J., \& SEGUI, J. (1990). Neighborhood frequency effects in visual word recognition: A comparison of lexical decision and masked identification latencies. Perception \& Psychophysics, 47, 191-198.

Guttentag, R. E., Haith, M. M., Goodman, G. S., \& Haugh, J. (1984). Semantic processing of unattended words by bilinguals: A test of the input switch mechanism. Journal of Verbal Learning \& Verbal Behavior, 23, 178-188.

IMBS, P. (1971). Études statistiques sur le vocabulaire français: Dictionnaire des fréquences. Vocabulaire littéraire des XIXe et XXe siècles (Centre de recherche pour un trésor de la langue française, CNRS). Nancy \& Paris: Librairie Marcel Didier.

JACOBS, A. M., \& GRAINGER, J. (1992). Testing a semistochastic variant of the interactive activation model in different word recognition experiments. Journal of Experimental Psychology: Human Perception \& Performance, 18, 1174-1188.

Klein, D., Zatorre, R. J., Milner, B., Meyer, E., \& Evans, A. C. (1995). The neural substrates of bilingual language processing: $E v-$ idence from positron emission tomography. In M. Paradis (Ed.), Aspects of bilingual aphasia (pp. 23-36). Oxford, U.K.: Pergamon.

Kolers, P. A. (1966). Reading and talking bilingually. American Journal of Psychology, 79, 357-376.

KUČERA, H., \& FranCIS, W. N. (1967). Computational analysis of present day American English. Providence, RI: Brown University Press.

MacNamara, J. (1967). The linguistic independence of bilinguals. Journal of Verbal Learning \& Verbal Behavior, 6, 729-736.

MACNAMARA, J., \& KUSHNiR, S. (1971). Linguistic independence of bilinguals: The input switch. Journal of Verbal Learning \& Verbal Behavior, 10, 480-487.

McClelland, J. L., \& Rumelhart, D. E. (1981). An interactiveactivation model of context effects in letter perception: Part 1. An account of basic findings. Psychological Review, 88, 375-405.

NAS, G. (1983). Visual word recognition in bilinguals: Evidence for a cooperation between visual and sound based codes during access to a common lexical store. Journal of Verbal Learning \& Verbal Behavior, 22, 526-534.

Obler, L., \& Albert, M. (1978). A monitor system for bilingual language processing. In M. Paradis (Ed.), Aspects of bilingualism (pp. 156-164). Columbia, SC: Hornbeam Press.

PaAP, K. R., Newsome, S. L., MCDonald, J. E., \& Schvaneveldt, R. W. (1982). An activation-verification model for letter and word recognition: The word-superiority effect. Psychological Review, 89, 573-594.

Petersen, S. E., Fox, P. T., Snyder, A., \& Raichle, M. E. (1990). Activation of prestriate and frontal cortical activity by words and wordlike stimuli. Science, 249, 1041-1044.

Scarborough, D. L., Gerard, L., \& Cortese, C. (1984). Independence of lexical access in bilingual word recognition. Journal of Verbal Learning \& Verbal Behavior, 23, 84-99. 
Segui, J., \& Grainger, J. (1990). Priming word recognition with orthographic neighbors: Effects of relative prime-target frequency. Journal of Experimental Psychology: Human Perception \& Performance, $16,65-76$

Simpson, G. B., \& Burgess, C. B. (1985). Activation and selection processes in the recognition of ambiguous words. Journul of Experimental Psychology: Human Perception \& Performance, 11, 28-39.

SNODGRASS, J. G., \& MinTZER, M. (1993). Neighborhood effects in visual word recognition: Facilitatory or inhibitory? Memory \& Cognition, 21, 247-266.

SoAres, C., \& Grosjean, F. (1984). Bilinguals in a monolingual and bilingual speech mode: The effect on lexical access. Memory \& Cognition, 12, 380-386.

SwINNEY, D. A. (1979). Lexical access during comprehension: (Re)Consideration of context effects. Journal of Verbal Learning \& Verbal Behavior, 18, 645-659.
Van Heuven, W., Dijkstra, T., \& Grainger, J. (1997). Orthographic neighborhood effects in bilingual word recognition. Manuscript submitted for publication.

\section{NOTES}

1. Extended simulation work on the BIA model with respect to the effects of within- and between-language orthographic neighbors and orthographic priming is currently underway. This simulation work will be reported in a separate theoretical paper describing the development and testing of the model.

2. Because of these constraints, some of the prime words were crosslanguage homographs. This arose mainly in the same-language condition, and therefore any influence of the homographic status of these primes would only be further evidence in favor of the nonselective access hypothesis.

APPENDIX A

Words Used in Experiment 1

\begin{tabular}{|c|c|c|c|c|c|}
\hline \multicolumn{2}{|c|}{ Same-Language Primes } & \multicolumn{4}{|c|}{ Different-Language Primes } \\
\hline Related & Unrelated & Target & Related & Unrelated & Target \\
\hline also & edge & ALTO & beau & donc & BEAM \\
\hline blue & desk & BLUR & vent & vite & BENT \\
\hline cook & june & $\mathrm{COOP}$ & bois & mois & BOIL \\
\hline cord & high & CURD & tard & peur & CARD \\
\hline done & just & DINE & coup & pire & CORP \\
\hline find & gold & FEND & trop & yeux & CROP \\
\hline gate & mark & GALE & dieu & venu & DIET \\
\hline more & neck & GORE & fils & race & FIGS \\
\hline help & rich & HELM & fois & cher & FOIL \\
\hline keep & post & KEEL & quel & bras & FUEL \\
\hline bank & king & BUNK & loin & noir & LOAN \\
\hline real & roof & HEAL & gens & ciel & GUNS \\
\hline land & moon & LARD & haut & fier & HALT \\
\hline less & sore & LOSS & joie & acte & JOIN \\
\hline left & very & LOFT & sens & vrai & LENS \\
\hline next & type & NEST & lire & oeil & LICE \\
\hline past & late & PEST & jour & cinq & SOUR \\
\hline read & edge & REAP & huit & vers & QUIT \\
\hline sell & fast & SILL & rire & lieu & RICE \\
\hline turn & near & TURF & sang & vide & SAND \\
\hline warm & fine & WARP & $\operatorname{tant}$ & nuit & TANK \\
\hline wild & poor & WELD & pied & pris & TIED \\
\hline fire & song & FARE & dame & oeuf & DOME \\
\hline hard & went & HERD & bout & agir & BOAT \\
\hline
\end{tabular}


APPENDIX B

Words Used in Experiment 2

\begin{tabular}{|c|c|c|c|c|}
\hline \multicolumn{2}{|c|}{ Same-Language Primes } & \multicolumn{2}{|c|}{ Different-Language Primes } & \multirow[b]{2}{*}{ Target } \\
\hline Related & Unrelated & Related & Unrelated & \\
\hline amant & mille & among & drive & AMONT \\
\hline suite & forme & quite & later & CUITE \\
\hline vaste & poser & taste & power & FASTE \\
\hline drame & train & trade & water & TRAME \\
\hline lire & flot & fire & once & CIRE \\
\hline gain & vert & rain & lost & BAIN \\
\hline cave & sang & came & full & CAGE \\
\hline chat & faim & shut ' & fear & CHUT \\
\hline louer & faute & lower & armed & LOGER \\
\hline plaie & crier & plane & loved & PLATE \\
\hline rider & lever & river & forms & RIMER \\
\hline route & chien & south & heart & SOUTE \\
\hline dent & réel & sent & blue & LENT \\
\hline haïr & vide & hate & care & HAIE \\
\hline fort & cher & post & wife & PORT \\
\hline mars & prix & mark & view & MARE \\
\hline verre & payer & serve & plant & VERVE \\
\hline paris & signe & paper & chief & PARER \\
\hline foule & jadis & house & style & HOULE \\
\hline range & prier & large & sides & LANGE \\
\hline note & oser & nice & near & NOCE \\
\hline rire & pays & rise & hair & RITE \\
\hline mien & hier & mile & meet & MIEL \\
\hline lune & $\operatorname{tard}$ & june & town & JUPE \\
\hline moyen & basse & dozen & fixed & DOYEN \\
\hline clair & prise & claim & plain & CLAIE \\
\hline soin & huit & soil & gray & SOIF \\
\hline vive & vite & live & cost & RIVE \\
\hline papa & bord & pale & fell & PAPE \\
\hline sauf & ceci & salt & else & SAUT \\
\hline
\end{tabular}

(Manuscript received June 9, 1995;

revision accepted for publication May 20, 1996.) 